\title{
Effects of Mushroom and Chicory Extracts on the Physiology and Shape of Prevotella intermedia, a Periodontopathogenic Bacterium
}

\author{
Caterina Signoretto, ${ }^{1}$ Anna Marchi, ${ }^{1}$ Anna Bertoncelli, ${ }^{1}$ Gloria Burlacchini, ${ }^{1}$ \\ Francesco Tessarolo, ${ }^{2}$ Iole Caola, ${ }^{3}$ Elisabetta Pezzati, ${ }^{1,4}$ Egija Zaura, ${ }^{5}$ \\ Adele Papetti, ${ }^{6}$ Peter Lingström, ${ }^{7}$ Jonathan Pratten, ${ }^{8}$ David A. Spratt, ${ }^{8}$ \\ Michael Wilson, ${ }^{8}$ and Pietro Canepari ${ }^{1}$ \\ ${ }^{1}$ Sezione di Microbiologia, Dipartimento di Patologia e Diagnostica, Università di Verona, Strada Le Grazie 8, 37134 Verona, Italy \\ ${ }^{2}$ Centro Interdipartimentale di Tecnologie Biomediche, Università di Trento, Via delle Regole 101, 38100 Trento, Italy \\ ${ }^{3}$ Sezione di Microscopia Elettronica, Dipartimento di Medicina di Laboratorio, APSS, 38100 Trento, Italy \\ ${ }^{4}$ DIPTERIS, Università di Genova, Corso Europa 26, 16132 Genova, Italy \\ ${ }^{5}$ Department of Preventive Dentistry, Academic Centre for Dentistry Amsterdam (ACTA), Gustav Mahlerlaan 3004, \\ 1081 LA Amsterdam, The Netherlands \\ ${ }^{6}$ Dipartmento di Chimica Farmaceutica, Università di Pavia, Via Taramelli 12, 27100 Pavia, Italy \\ ${ }^{7}$ Department of Cariology, Institute of Odontology at Sahlgrenska Academy, University of Gothenburg, P.O. Box 450, \\ 40530 Göteborg, Sweden \\ ${ }^{8}$ Department of Microbial Diseases, UCL Eastman Dental Institute, 256 Gray's Inn Road, London WC1X 8LD, UK
}

Correspondence should be addressed to Pietro Canepari, pietro.canepari@univr.it

Received 15 June 2011; Accepted 11 July 2011

Academic Editor: Carla Pruzzo

Copyright ( 12011 Caterina Signoretto et al. This is an open access article distributed under the Creative Commons Attribution License, which permits unrestricted use, distribution, and reproduction in any medium, provided the original work is properly cited.

Contrary to the common assumption that food has a negative impact on oral health, research has shown that several foods contain a number of components with antibacterial and antiplaque activity. These natural compounds may be useful for improving daily oral hygiene. In this study we evaluate the mode of antimicrobial action of fractions of mushroom and red chicory extracts on Prevotella intermedia, a periodontopathogenic bacterium. The minimal inhibitory concentration corresponded to $0.5 \mathrm{x}$ compared to the natural food concentration for both extracts. This concentration resulted in a bacteriostatic effect in mushroom extract and in a slightly bactericidal effect in chicory extract. Cell mass continued to increase even after division stopped. As regards macromolecular synthesis, DNA was almost totally inhibited upon addition of either mushroom or chicory extract, and RNA to a lesser extent, while protein synthesis continued. Cell elongation occurred after septum inhibition as documented by scanning electron microscopy and cell measurement. The morphogenetic effects are reminiscent of the mode of action of antibiotics such as quinolones or $\beta$-lactams. The discovery of an antibiotic-like mode of action suggests that these extracts can be advantageously employed for daily oral hygiene in formulations of cosmetic products such as mouthwashes and toothpastes.

\section{Introduction}

Periodontal diseases include a sizeable group of pathological alterations of the periodontal tissue. The commonest forms of the disease are gingivitis and periodontitis, and these figure among the most widespread human infectious diseases $[1,2]$. Both are dental plaque-associated pathologies $[3,4]$. Gingivitis is very common and is characterized by reversible inflammation in the marginal periodontal tissues while periodontitis is an inflammation-based infection of the support structure of the teeth with progressive destruction of them that can result in dental loss. The commonest form of periodontitis is adult chronic periodontitis $[1,2]$. Although several factors including systemic pathologies such as diabetes and immunosuppression or environmental factors such as smoking are capable of contributing to the severity of periodontal 
diseases, bacterial infection is considered to be the leading cause [5]. As far as adult chronic periodontitis is concerned, the role of a bacterial consortium of the dental plaque, mainly composed of gram-negative strict anaerobes has been demonstrated [5-7]. Prevotella intermedia is one of these potential periodontopathogenic bacterial species. Several virulence factors including fimbriae, hydrolases, hemolysins, hemagglutinins, and lipopolysaccharides have been detected in this microorganism and confer bacterial coaggregation capability, adhesion to epithelial cells, invasion of epithelial cells, and induction of inflammatory lympho-, chemo-, and cytokines $[5,8]$.

It is generally accepted that lowering the oral bacterial biomass is an effective method for curing and/or preventing bacterial oral pathologies. The manual dexterity of many individuals, however, is not efficient enough for them to obtain good oral hygiene, and therefore several methods have been proposed in order to assist such people. The simpler the methods are the more diffuse and effective they prove. In this context, products for regular daily oral hygiene such as mouthwashes and toothpastes which contain compounds endowed with antimicrobial and antiplaque activities are considered excellent candidates.

Contrary to the commonly held opinion that food has a negative impact on oral health, research conducted over the past three decades has shown that several foods contain a number of components endowed with antibacterial and antiplaque activity $[9,10]$. Very recently, it has been shown that regular consumption of foods enriched with these active molecules is associated with modification of the oral microbial community in the direction of less periodontopathogenic microbiota [11]. It therefore seems reasonable to encourage the consumption of such foods and/or to incorporate the active compound(s) in cosmetic products for daily oral hygiene. Previous studies have shown antimicrobial and antiplaque activities in low-molecular-mass (LMM) fractions of extracts from both an edible mushroom (Lentinus edodes, very popular in Japan and called shiitake) or from Italian red chicory (early Treviso red chicory, an anthocyanic cultivar of Cichorium intybus) $[12,13]$.

In this work we evaluate the mode of antimicrobial action of fractions of these two natural extracts on P. intermedia.

\section{Materials and Methods}

2.1. Bacterial Strain and Growth Conditions. P. intermedia ATCC 25611 was used throughout this study. This strain was grown in Brain Hearth Infusion (BHI, Oxoid Ltd., Basingstoke, UK) broth to which $5 \mu \mathrm{g} / \mathrm{mL}$ hemin and $1 \mu \mathrm{g} / \mathrm{mL}$ vitamin K (Sigma-Aldrich Co., St. Louis, MO, USA) were added (BHI+HK) or in Blood Agar (BA, Oxoid) plates. Cultures in both liquid and solid media were incubated at $37^{\circ} \mathrm{C}$ in an anaerobic chamber (Whitley DG 250 Anaerobic Workstation, Don Whitley Scientific, Shipley, UK) with an atmosphere composed of $85 \%$ nitrogen, $10 \%$ hydrogen, and $5 \% \mathrm{CO}_{2}$. In some experiments growth of $P$. intermedia in a biofilm structure was allowed on ceramic hydroxyapatite (HA) discs (Clarkson Chromatography Products Inc., South
Williamsport, PA, USA). To achieve this, HA discs $(2.5 \mathrm{~mm}$ diameter) were coated with sterile human saliva collected from a pool of donors. Each disc was then incubated in $5 \mathrm{~mL}$ of BHI+HK medium spread with a $P$. intermedia culture in a well of a 6-well tissue culture plate $(35 \mathrm{~mm}$ diameter, flat bottom, Sarstedt, Verona, Italy) at $37^{\circ} \mathrm{C}$ in the anaerobic atmosphere. Every day (for a total of five days) culture supernatants were removed by gentile aspiration and replaced with fresh preconditioned medium. In order to analyse the effects of the test compound, on day 4 suitable dilutions of LMM fractions of either mushroom or chicory extract were added to the growth medium following incubation for an additional 15 hours. At the end of each incubation, biofilms were washed three times with sterile distilled water and then fixed with $2.5 \%$ glutaraldehyde in $0.1 \mathrm{M}$ phosphate buffer $\mathrm{pH}$ 7.2 for SEM analysis.

2.2. LMM Fractions of Both Mushroom and Chicory Extracts. Aqueous extracts of both shiitake mushroom and red chicory and separation by ultrafiltration of the LMM $(<5,000$ Daltons) fraction were performed as described elsewhere [13]. LMM fractions were lyophilised and stored up to 3 months at $-80^{\circ} \mathrm{C}$. Immediately before use, a sample was rehydrated with sterile distilled water to obtain a $10 \mathrm{x}$ solution and kept at $4^{\circ} \mathrm{C}$ for no longer than a week. The $1 \mathrm{x}$ concentration of the LMM fraction after reconstitution represents the original concentration in the food.

2.3. Evaluation of Cell Growth and Viability. Optical density (O.D.) was measured at $640 \mathrm{~nm}$ wavelength with a Beckman mod. DU 530 spectrophotometer. Total bacteria were counted as cell particles with a Coulter Counter mod ZBI (Coulter Scientific) equipped with a $30 \mu \mathrm{m}$ capillary. Viable cells were determined as colony forming units (CFU) per $\mathrm{mL}$ of culture. Suitable dilutions in sterile saline solution of the untreated and treated cultures were plated in BA plates and incubated at $37^{\circ} \mathrm{C}$ for 48 hours in the anaerobic atmosphere.

2.4. Evaluation of DNA, RNA, and Protein Synthesis. Aliquots of an exponentially growing culture ( $150 \mu \mathrm{L}$, O.D. 0.2 unit) were placed in the wells of a microtitre plate together with $5 \mu \mathrm{Ci}$ of $\left[{ }^{3} \mathrm{H}\right]$ thymidine (spec. act. $>10 \mathrm{Ci} / \mathrm{mmol}$ ) or $\left[{ }^{3} \mathrm{H}\right]$ uridine (spec. act. $>20 \mathrm{Ci} / \mathrm{mmol}$ ) or $\left[{ }^{3} \mathrm{H}\right]$ leucine (spec. act. $50 \mathrm{Ci} / \mathrm{mmol}$, PerkinElmer Life and Analytical Science, Boston, MA, USA). In some wells suitable dilutions of the test compounds were added. Each determination was performed in triplicate. Microtiter plates were incubated at $37^{\circ} \mathrm{C}$ in the anaerobic atmosphere for $60 \mathrm{~min}$. At the end of this time period the culture was overlaid on a Millipore GF/C glass fibre paper soaked in advance with 10\% trichloroacetic acid (TCA) and plunged in a cold 10\% TCA solution. Filters were then washed three times with cold TCA and, finally, twice with acetone. Radioactivity was determined with a Beckman LS 6500 liquid scintillation counter. Three distinct identical experiments were performed.

2.5. Scanning Electron Microscopy (SEM). SEM was performed within a week of fixation of the samples. Glutaraldehyde-fixed samples from both planktonic and biofilm 
TABLE 1: Macromolecular synthesis of $P$. intermedia treated for 60 min with different concentrations of LMM fractions of both mushroom and chicory extracts.

\begin{tabular}{|c|c|c|c|c|}
\hline \multirow{2}{*}{ LMM fraction } & \multirow[t]{2}{*}{ Concentration } & \multicolumn{3}{|c|}{ Macromolecular synthesis ( $\%$ of untreated control) } \\
\hline & & DNA & RNA & Protein \\
\hline \multirow{4}{*}{ Mushroom } & 0 & $100^{\mathrm{b}}$ & $100^{\mathrm{b}}$ & $100^{\mathrm{b}}$ \\
\hline & $0.25 \mathrm{x}^{\mathrm{a}}$ & 19 & 47 & 83 \\
\hline & $0.5 \mathrm{x}$ & 9 & 22 & 48 \\
\hline & $1 \mathrm{x}$ & 5 & 5 & 36 \\
\hline \multirow{4}{*}{ Chicory } & 0 & $100^{\mathrm{c}}$ & $100^{\mathrm{c}}$ & $100^{c}$ \\
\hline & $0.25 \mathrm{x}^{\mathrm{a}}$ & 22 & 53 & 79 \\
\hline & $0.5 \mathrm{x}$ & 11 & 26 & 54 \\
\hline & $1 \mathrm{x}$ & 8 & 4 & 32 \\
\hline
\end{tabular}

${ }^{\mathrm{a}}$ Subinhibitory dose.

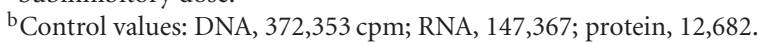

${ }^{\mathrm{c} C}$ Control values: DNA, 347,012 cpm; RNA, 129,647; protein, 11,239.

TABle 2: Cell length measurement of P. intermedia cells treated for two hours with different concentrations of LMM fraction of both mushroom or chicory extracts in comparison with control cells at the same time.

\begin{tabular}{|c|c|c|c|c|c|c|}
\hline \multirow{2}{*}{ Microorganism } & \multirow{2}{*}{ Growth condition } & \multicolumn{5}{|c|}{ Cell length $(\mu \mathrm{m})$} \\
\hline & & Mean & SD & Min value & Max value & Mode \\
\hline \multirow{5}{*}{ P. intermedia } & Control & 1.09 & 0.41 & 0.54 & 3.01 & 0.75 \\
\hline & Mushroom $0.25 \mathrm{x}^{\mathrm{a}}$ & 1.83 & 0.88 & 0.64 & 4.97 & 0.91 \\
\hline & Mushroom 0.5x & 1.94 & 1.09 & 0.72 & 7.40 & 1.38 \\
\hline & Chicory $0.25 \mathrm{x}^{\mathrm{a}}$ & 2.07 & 0.93 & 0.68 & 5.06 & 0.97 \\
\hline & Chicory $0.5 x$ & 2.37 & 1.36 & 0.76 & 9.09 & 1.32 \\
\hline
\end{tabular}

${ }^{a}$ Subinhibitory dose.

cultures were washed three times with phosphate buffer followed by three rinses in distilled water. Specimens were then serially dehydrated in ethanol and subjected to criticalpoint drying with $\mathrm{CO}_{2}$, mounted on metal stubs and sputtercoated with gold. Each specimen was viewed with an ESEM FEG XL30 electron microscope (Fei-Philips) at magnifications of $\times 5,000$ to $\times 40,000$. Cell length measurement was performed on 150 bacteria at $\times 5,000$ magnification.

\section{Results}

3.1. Effects of LMM Fractions of Both Mushroom and Chicory Extracts on Cell Growth and Viability of P. intermedia. Different concentrations of the LMM fractions of both mushroom and chicory extracts ranging from 0.25 to $1 \mathrm{x}$ were tested in growing $P$. intermedia. Figure 1 shows the effects of these concentrations on increases in optical density, cell particle number, and cell viability in $P$. intermedia. As far as the LMM fraction of mushroom extract is concerned, the concentration of $0.5 \mathrm{x}$ was the minimum dose capable of inhibiting cell division, as evaluated by cell particle counts. At this concentration a bacteriostatic effect was observed, as well as a slight increase in O.D. in the course of the experiment. Higher concentrations (e.g., 1x) had a partial bactericidal effect with a 50\% decrease in viable cells. Similar results were obtained when LMM fraction of chicory extract was tested: again the minimal dose capable of inhibiting cell division was $0.5 \mathrm{x}$, but, as opposed to the same concentration of mushroom extract, this concentration reduced cell viability by $50 \%$.

\subsection{Effects of LMM Fractions of Both Mushroom and Chicory} Extracts on Macromolecular Synthesis of P. intermedia. DNA, RNA and protein synthesis of $P$. intermedia were evaluated in the presence of the active concentrations reported above. Table 1 summarises the results: a strong inhibitory effect on DNA synthesis was observed during treatment with $1 \mathrm{x}$ and $0.5 \mathrm{x}$ concentrations of both mushroom and chicory extracts with a residual synthesis lower than $10 \%$ of the untreated control. The $0.25 \mathrm{x}$ subinhibitory concentration allowed roughly 20\% DNA synthesis. RNA synthesis, albeit to a lesser extent compared with DNA synthesis, was reduced to roughly $25 \%$ and $50 \%$ of the control in the presence of $1 \mathrm{x}$ and $0.5 x$, respectively, no matter whether mushroom or chicory was tested. The $1 \mathrm{x}$ concentration strongly inhibited RNA synthesis. Protein synthesis was inhibited by $50 \%$ in the presence of $0.5 \mathrm{x}$ while $1 \mathrm{x}$ induced greater inhibition (70\%). A reduction of only about $20 \%$ in protein synthesis was observed at $0.25 x$.

\subsection{Morphological Examination and Cell Size Distribution of P. intermedia Treated with LMM Fractions of Mushroom and Chicory Extracts. Bacteria treated as above were also collect- ed for morphological analysis by both optical and scanning electron microscopy (SEM). Preliminary observation by op- tical microscopy showed the presence of elongated cells as a result of the treatment. Thus, we resorted to SEM analysis in order to precisely evaluate cell size and distribution. Figure 2 shows the appearance of $P$. intermedia during treatment with mushroom or chicory extracts. Distinctly elongated}



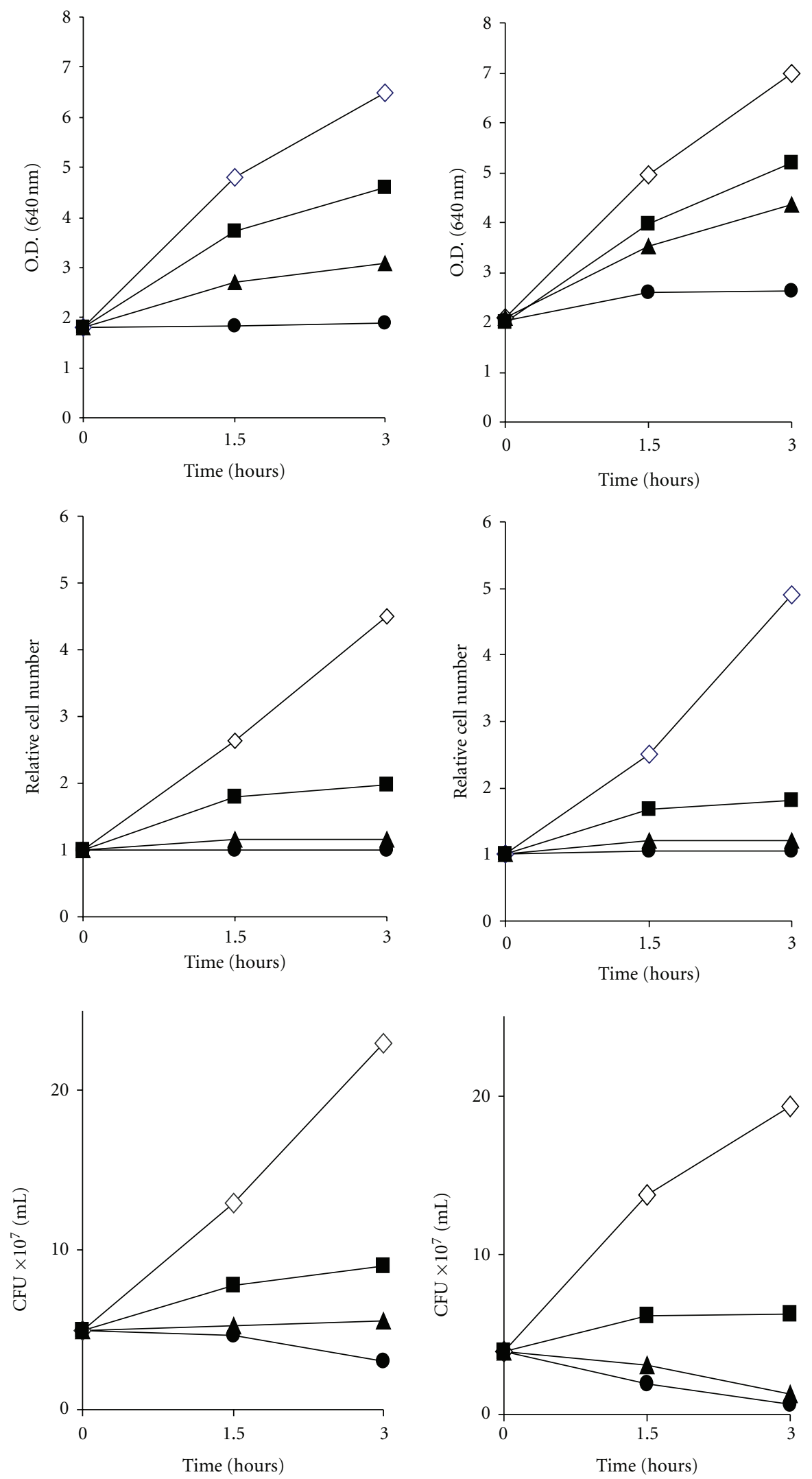

(a)

(b)

Figure 1: Effects on cell mass, cell number, and cell viability of $P$. intermedia treated with different concentrations of LMM fraction of mushroom (column (a)) and chicory (column (b)) extracts. Symbols: $(\diamond)$ untreated control, $(\mathbf{\square}) 0.25 \mathrm{x},(\boldsymbol{\Delta}) 0.5 \mathrm{x},(\boldsymbol{\bullet}) 1 \mathrm{x}$ concentration. 


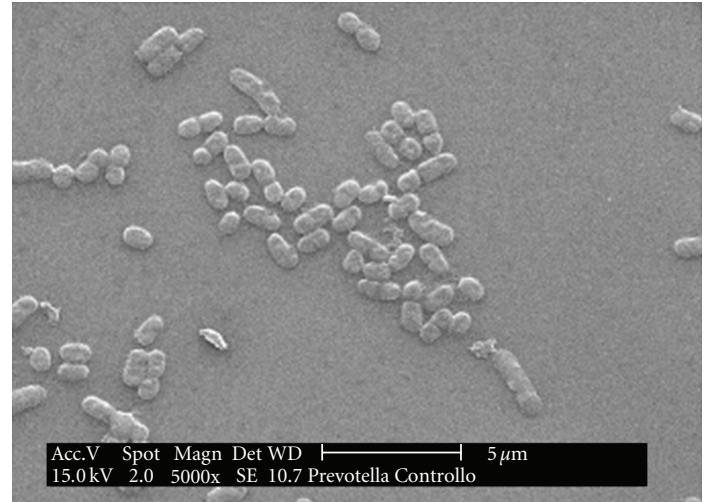

(a)

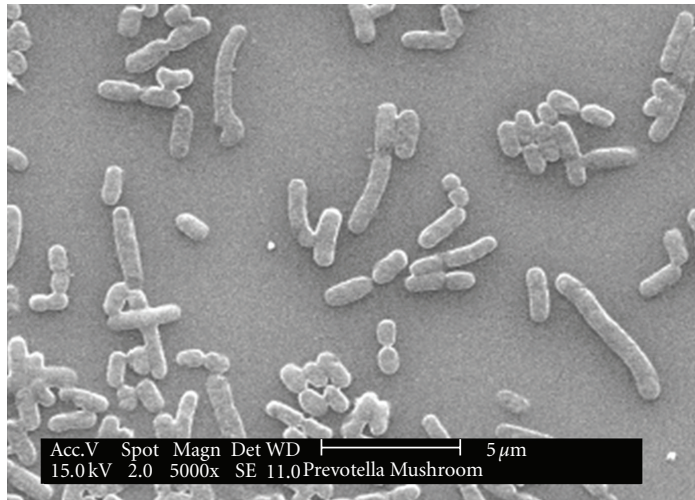

(b)

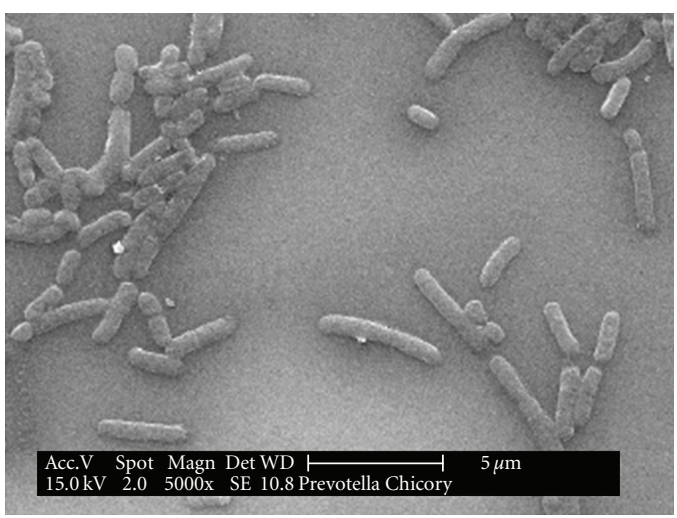

(c)

FIGURE 2: Scanning electron microscopy of untreated P. intermedia (a) and after a three-hour treatment with $0.5 \mathrm{x}$ of LMM fraction of mushroom (b) and chicory (c) extracts.

cells and several filaments with interrupted septa were seen after a three-hour treatment while untreated control cells prevalently presented the typical shape of short rods/coccobacilli. Table 2 shows the mean cell lengths with additional parameters of the treated cells in comparison with the untreated ones. Cell measurements confirmed the morphological observations at the inhibitory concentration. However, it is worthy of note that elongation was also observed in cells treated with a subinhibitory concentration $(0.25 \mathrm{x})$. Furthermore, analysis of the size distribution of untreated control and treated $P$. intermedia cells confirmed cell elongation following treatment (Figure 3). In a further set of experiments we evaluated the effects of the extracts on $P$. intermedia biofilm architecture. Figure 4 shows that untreated control biofilm appeared as a compact structure with bacteria close to one another, while in treated biofilms, both with mushroom and with chicory (the latter not shown in the figure), several gaps were observable.

\section{Discussion}

A substantial number of in vitro studies have shown that components of vegetal food exert intrinsic antibacterial, antiadhesive and antiplaque activity $[9,10]$. The main family of substances endowed with such activity is that of the polyphenolic substances. These properties have been mainly detected against oral bacteria, although microorganisms responsible for infections of other human sites (e.g., lower urinary tract) may interact with them $[14,15]$. These observations suggest that a diet rich in polyphenols may be useful for preventing the development of oral microbial pathologies, especially those known as plaque-dependent pathologies, such as caries and gingivitis/periodontitis. Hence, the main repercussion may be the development of so-called functional foods, that is, foods enriched with healthy substances. At the same time active compounds may be included in mouthwashes and toothpastes for daily oral hygiene. Although a large number of studies have been conducted to evaluate the efficacy of these compounds in terms of antimicrobial, antiadhesive, and antiplaque activity, very little is known about their mode of antibacterial action. The main goal of this research was precisely to try to elucidate this aspect. Throughout the study we used $P$. intermedia, one of the microorganisms included in a polymicrobial complex (mainly composed of strict anaerobe bacteria) which is involved in the etiology of adult chronic periodontitis, a pathology present worldwide and currently considered (together with dental caries) the commonest infectious disease. We evaluated the mechanism of antimicrobial action of LMM $(<5,000 \mathrm{Da})$ fractions of aqueous extracts from both mushroom (shiitake) and red chicory $[12,13]$. Test concentrations were referred to the original food concentrations. The minimal active concentration was $0.5 \mathrm{x}$ for both mushroom and chicory 


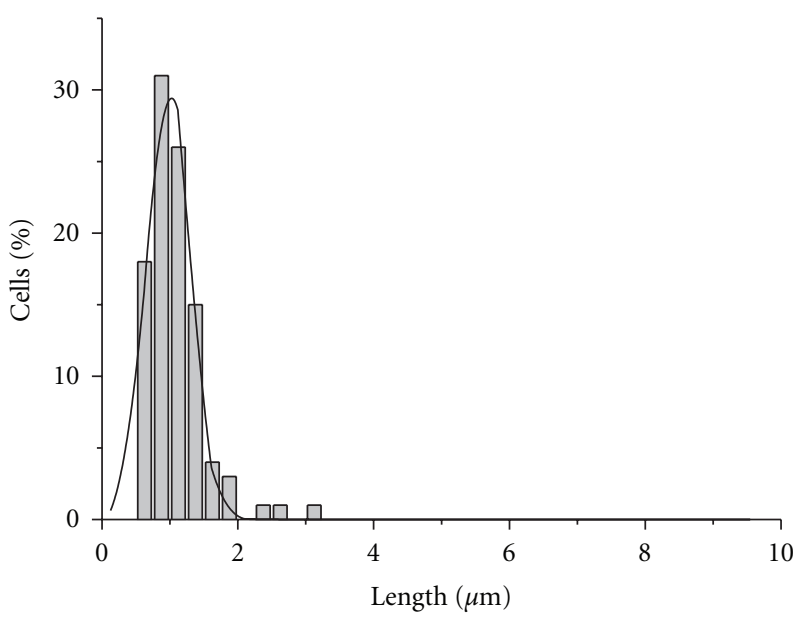

(a)

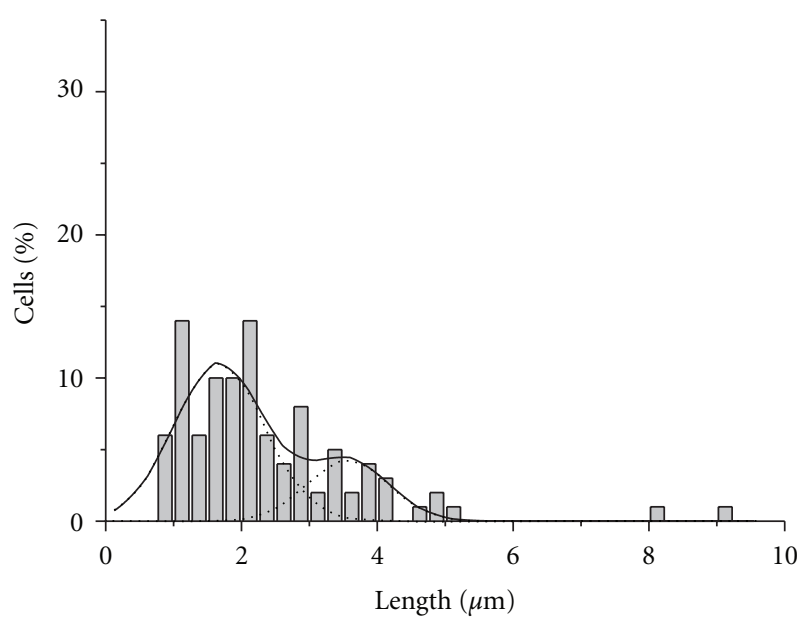

(c)

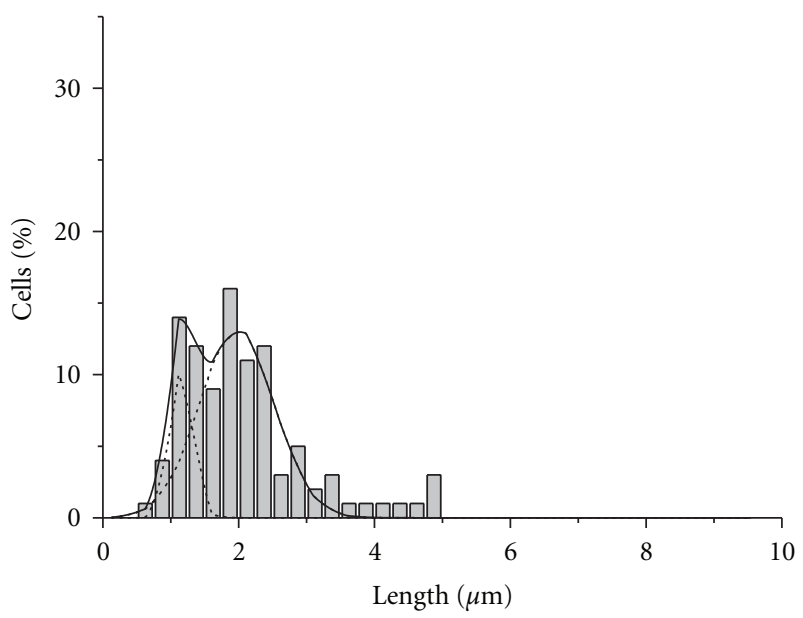

(b)

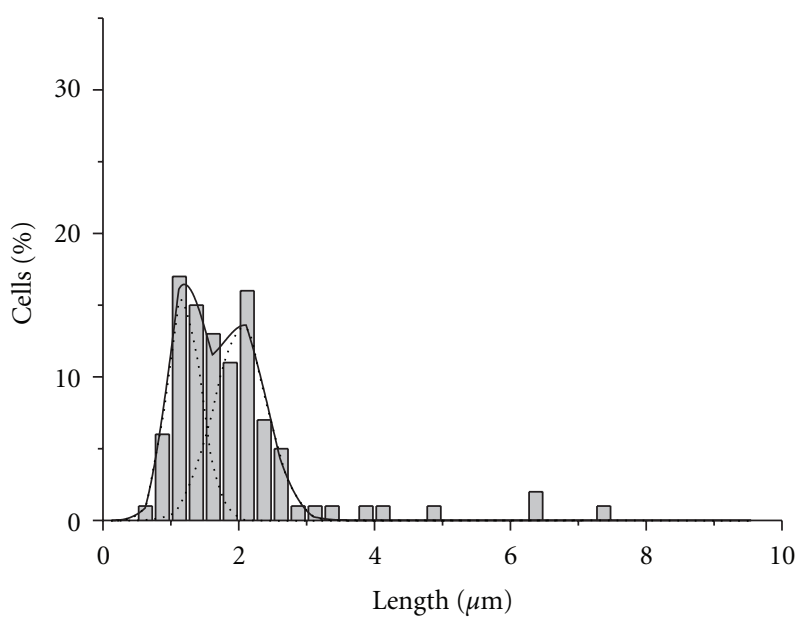

(d)

Figure 3: Cell length distribution of P. intermedia (a) and after a three-hour treatment with $0.5 \mathrm{x}$ chicory extract (b), and $0.5 \mathrm{x}$ (c) and $0.25 \mathrm{x}$ (d) mushroom extracts.

extracts. This concentration of mushroom extract acted bacteriostatically while the same concentration of chicory extract was slightly bactericidal after a three-hour treatment. At this concentration DNA synthesis was almost totally inhibited while RNA was inhibited to a lesser extent than DNA. Protein synthesis was only partially inhibited. The persistence of protein synthesis over time allows a cell mass increase, as indicated by the increase in O.D., producing cell filamentation, as revealed by SEM observation. In fact, nonseptate long rods and filaments were observed after treatment in comparison with untreated controls. These data suggest that the main target of action of both mushroom and chicory extracts is DNA synthesis. As a result of this, inhibition of septum formation occurs, but, as expected for rod-shaped bacteria, elongation still occurs. Morphological changes are compatible with the observation that protein synthesis persists (about 50\% of the untreated control) and O.D. increases over time. This mode of action is reminiscent of that described for antibiotics belonging to the quinolone family (e.g., ciprofloxacin) [16]. These chemotherapeutic agents primarily block DNA synthesis followed by septum formation inhibition and cell filamentation. A similar mode of action has been described for $\beta$-lactam antibiotics (e.g., penicillins and cephalosporins). In this case septum inhibition via blockade of the "penicillin binding protein" involved in septum synthesis is the main target of action, and, in this example too, filamentation occurs after septum inhibition [17]. Thus, a mode of action comparable with that of antibiotics may be supposed for these natural extracts. This statement is further supported by the observation that sub-MICs display morphogenetic effects such as those induced by the MIC and higher doses, as previously demonstrated for both $\beta$-lactams and quinolones $[16,18]$. Thus, this preliminary report indicates that a specific mode of action exists and the identification of specific target(s) is needed. This result suggests that these extracts could be used to advantage for daily oral hygiene in formulations of cosmetic products such as mouthwashes and toothpastes. The possibility of developing cosmetic products in which the active compound or compounds are natural molecules supports the tendency of consumers to prefer natural compounds to those obtained by chemical synthesis. Furthermore, foods enriched with 


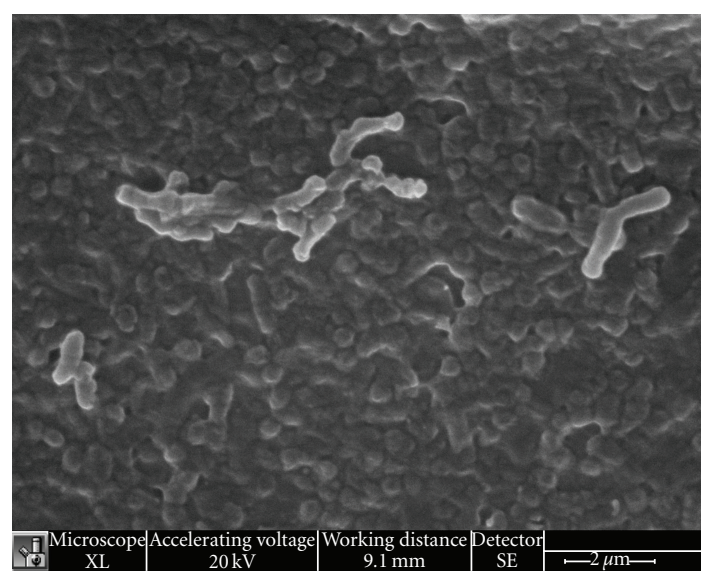

(a)

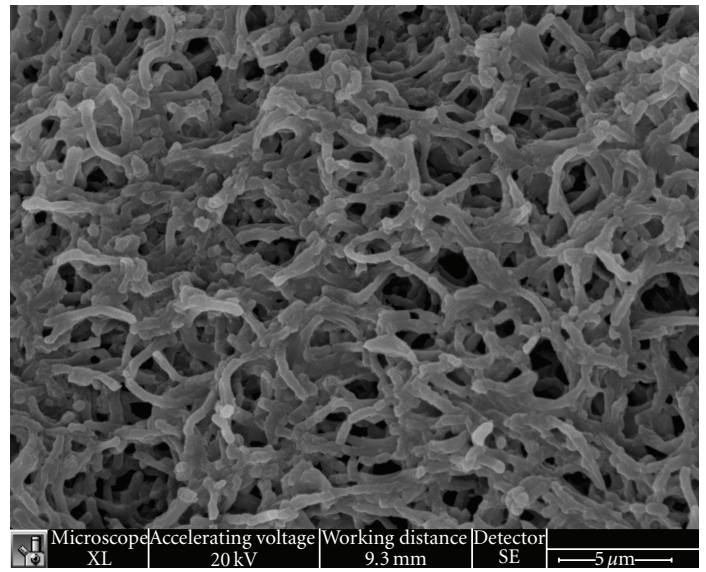

(c)

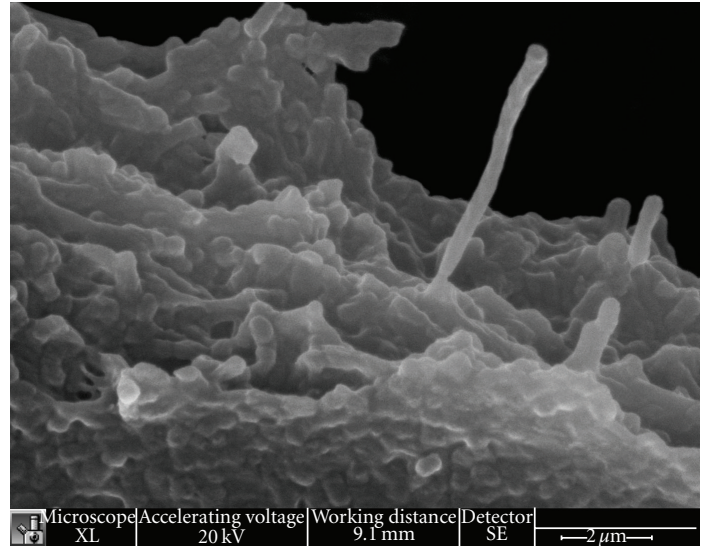

(b)

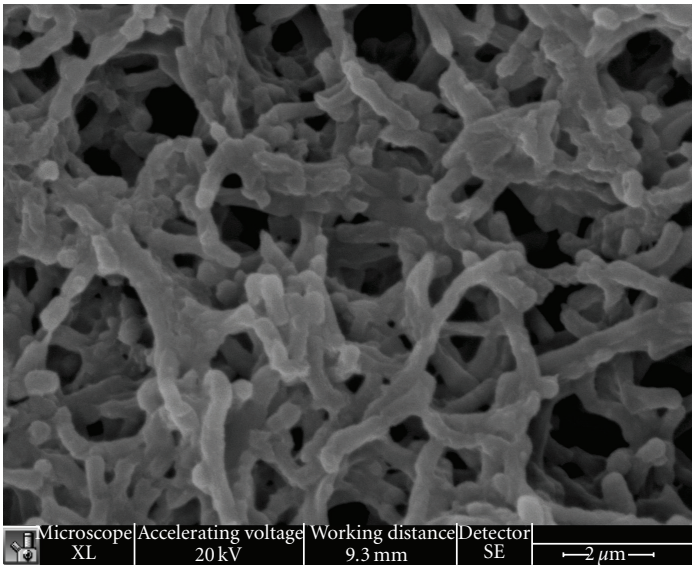

(d)

FIGURE 4: Scanning electron microscopy of $P$. intermedia grown in biofilm state ( $\mathrm{a}$ and $\mathrm{b}$ ) and after treatment with $0.5 \mathrm{x}$ mushroom extract (c and d).

these active compounds may be of great interest particularly in developing countries where severer economic conditions militate against the use of commercially available products for regular oral hygiene.

\section{Acknowledgment}

The research leading to these results has received funding from the European Union's Sixth Framework Programme (FP6) under the contract FOOD-CT-2006-036210 (project NUTRIDENT).

\section{References}

[1] P. D. Marsh and M. V. Martin, Oral Microbiology, Churchill Livingstone, Edinburgh, UK, 5th edition, 2009.

[2] R. J. Lamont, R. A. Burne, M. S. Lantz, and D. J. Leblanc, Oral Microbiology and Immunology, American Society for Microbiology Press, Washington, DC, USA, 2006.

[3] N. H. Newman and M. Wilson, Dental Plaque Revisited: Oral Biofilms in Health and Diseases, Bioline, Cardiff, UK, 1999.

[4] P. D. Marsh, "Dental plaque: biological significance of a biofilm and community life-style," Journal of Clinical Periodontology, vol. 32, supplement 6, pp. 7-15, 2005.
[5] S. S. Socransky and A. D. Haffajee, "Periodontal microbial ecology," Periodontology 2000, vol. 38, no. 2, pp. 135-187, 2005.

[6] L. A. Ximénez-Fyvie, A. D. Haffajee, and S. S. Socransky, "Comparison of the microbiota of supra- and subgingival plaque in health and periodontitis," Journal of Clinical Periodontology, vol. 27, no. 9, pp. 648-657, 2000.

[7] T. Nishihara and T. Koseki, "Microbial etiology of periodontitis," Periodontology 2000, vol. 36, no. 1, pp. 14-26, 2004.

[8] P. J. Ezzo and C. W. Cutler, "Microorganisms as risk indicators for periodontal disease," Periodontology 2000, vol. 32, no. 1, pp. 24-35, 2003.

[9] M. M. Cowan, "Plant products as antimicrobial agents," Clinical Microbiology Reviews, vol. 12, no. 4, pp. 564-582, 1999.

[10] C. Signoretto, P. Canepari, C. Pruzzo, and G. Gazzani, "Anticaries and antiadhesive properties of food constituents and plant extracts and implications for oral health," in Food Constituents and Oral Health: Current Status and Future Prospects, M. Wilson, Ed., Woodhead Publishing Limited, Cambridge, UK, 2009.

[11] C. Signoretto, F. Bianchi, G. Burlacchini, F. Sivieri, D. Spratt, and P. Canepari, "Drinking habits are associated with changes in the dental plaque microbial community," Journal of Clinical Microbiology, vol. 48, no. 2, pp. 347-356, 2010. 
[12] M. Daglia, A. Papetti, D. Mascherpa et al., "Vegetable food components with potentil activity on the development of microbial oral deseases," Journal of Biomedicine and Biotechnology. In press.

[13] D. A. Spratt, "Evaluation of the beneficial oral health properties of plant and fungal extracts," Journal of Biomedicine and Biotechnology. In press.

[14] I. Ofek, J. Goldhar, D. Zafriri, H. Lis, R. Adar, and N. Sharon, "Anti-Escherichia coli adhesin activity of cranberry and blueberry juices," New England Journal of Medicine, vol. 324, no. 22, p. 1599, 1991.

[15] A. B. Howell, N. Vorsa, A. D. Marderosian, and L. Y. Foo, "Inhibition of the adherence of P-fimbriated Escherichia coli to uroepithelial-cell surfaces by proanthocyanidin extracts from cranberries," New England Journal of Medicine, vol. 339, no. 15, pp. 1085-1086, 1998.

[16] P. G. Higgins, A. C. Fluit, and F. J. Schmitz, "Fluoroquinolones: structure and target sites," Current Drug Targets, vol. 4, no. 2, pp. 181-190, 2003.

[17] B. G. Spratt, "Distinct penicillin binding proteins involved in the division, elongation, and shape of Escherichia coli K 12," Proceedings of the National Academy of Sciences of the United States of America, vol. 72, no. 8, pp. 2999-3003, 1975.

[18] J. Buijs, A. S. M. Dofferhoff, J. W. Mouton, J. H. T. Wagenvoort, and J. W. M. Van Der Meer, "Concentration-dependency of $\beta$-lactam-induced filament formation in Gram-negative bacteria," Clinical Microbiology and Infection, vol. 14, no. 4, pp. 344-349, 2008. 

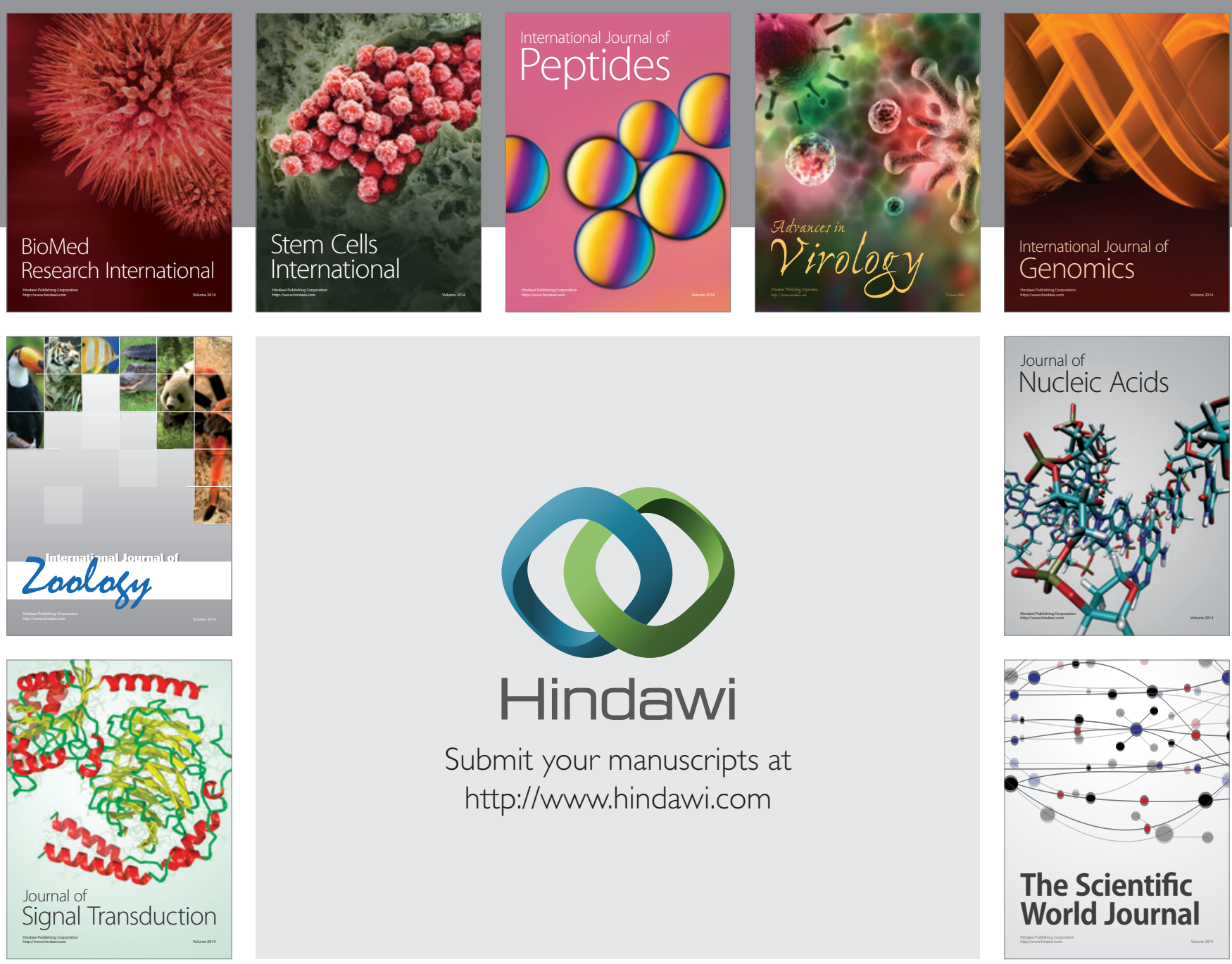

Submit your manuscripts at

http://www.hindawi.com
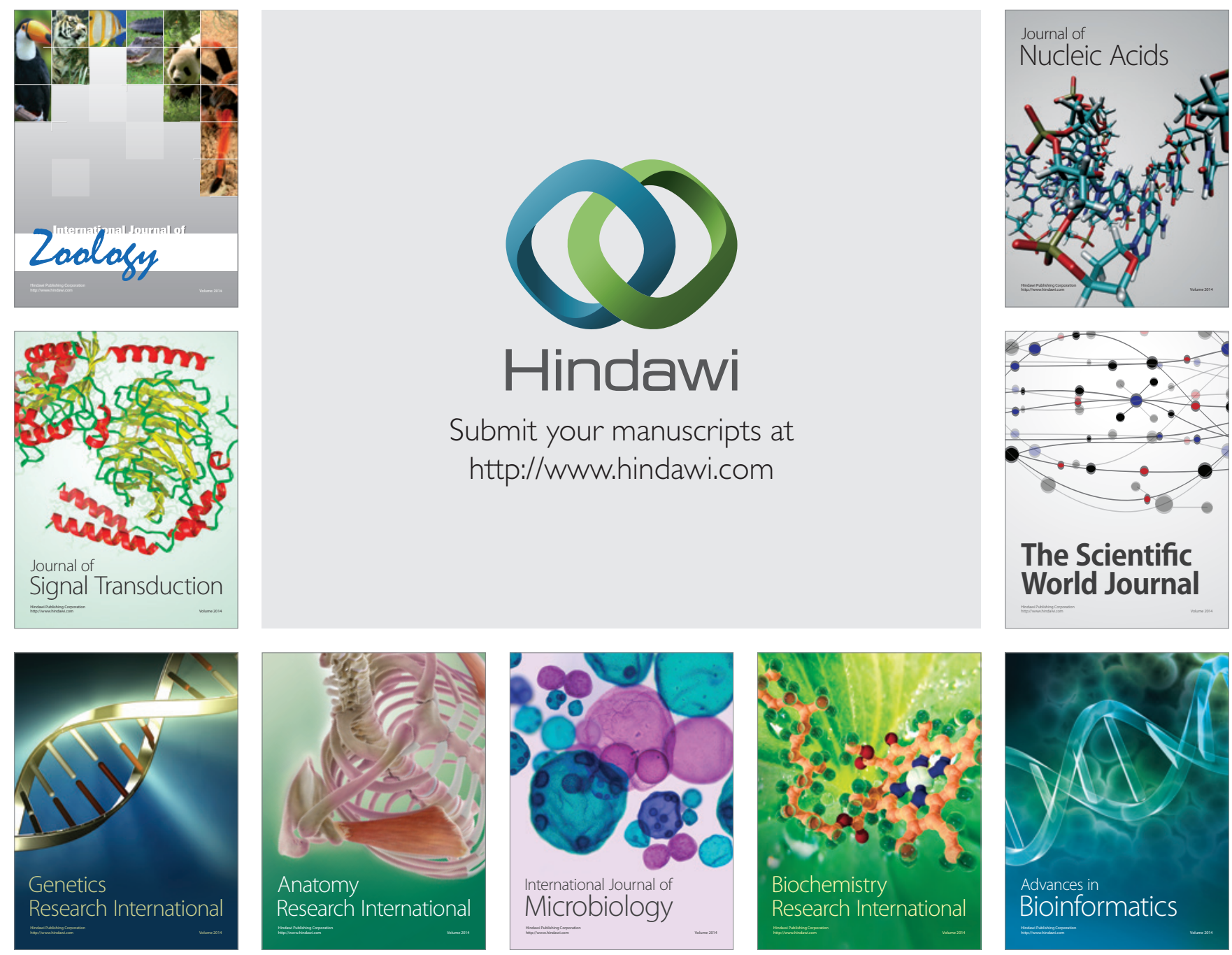

The Scientific World Journal
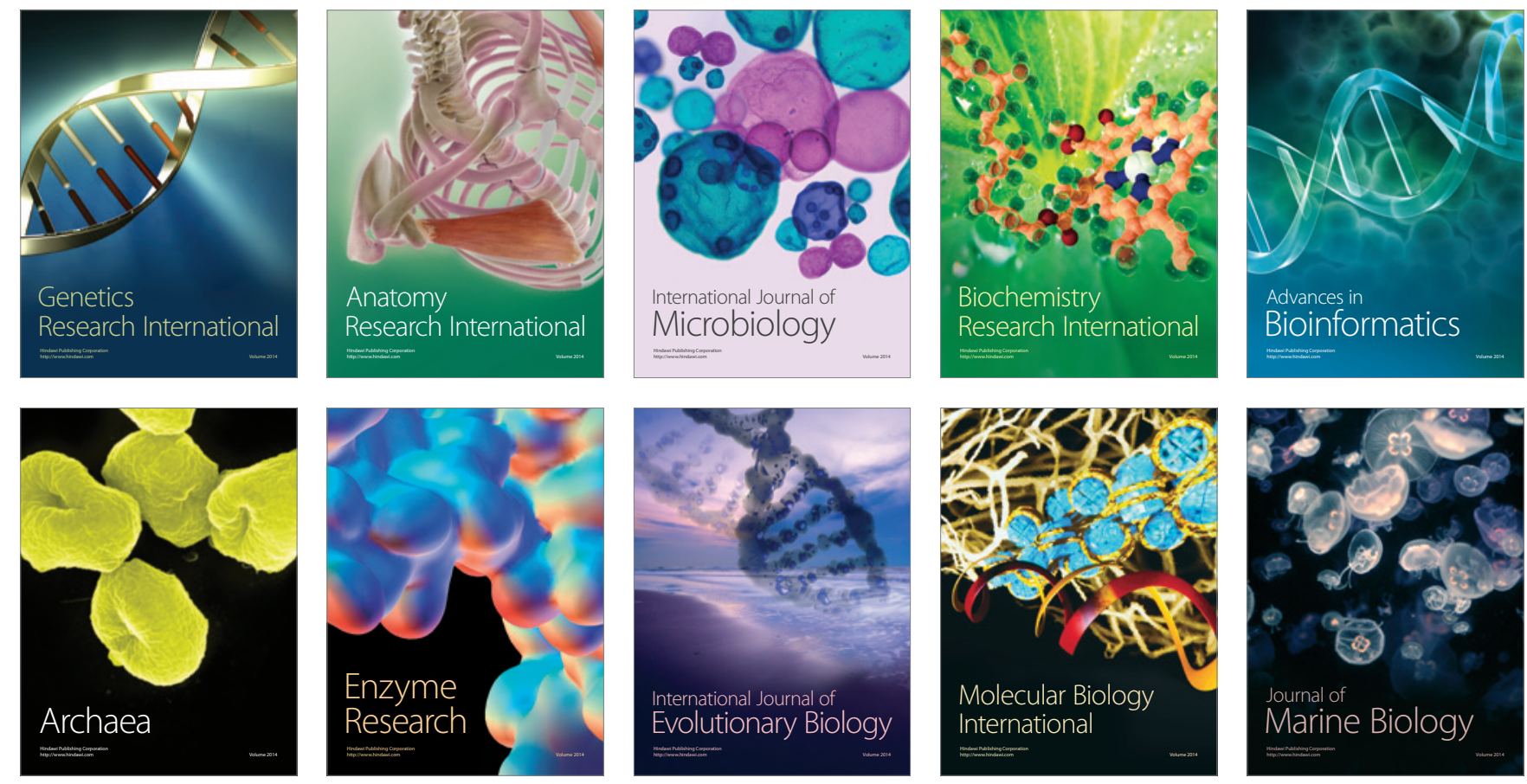